\title{
Uso de antagonistas e produtos alternativos no manejo pós-colheita de podridão mole em pimentão ${ }^{1}$
}

\author{
Use of antagonists and alternative products to manage post-harvest soft rot in pepper
}

\author{
Matheus Silva e Silva ${ }^{2}$, Francisco Conrado Queiroz Carvalho ${ }^{2}$, Jéssica Rodrigues da Silva ${ }^{2}$, Severina Rodrigues \\ de Oliveira Lins² e Sônia Maria Alves de Oliveira ${ }^{3 *}$
}

\begin{abstract}
RESUMO - Visando o controle da podridão mole causada por Pectobacterium carotovorum subsp. carotovorum (Pcc) em pimentão, foram avaliados 10 tratamentos: Bacillus spp.: isolado C116 (B. pumilus); Leveduras: isolados Lma

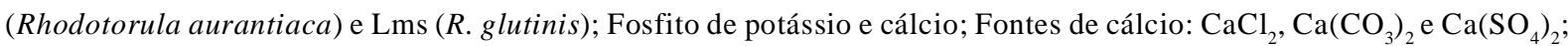
fungicida/bactericida orgânico Antica ${ }^{\circledR}$; antibiótico Kasumin ${ }^{\circledR}$. Após a determinação da concentração dos antagonistas e produtos alternativos pelo teste do antibiograma, foi realizado o teste in vivo, pela inoculação do patógeno, seis horas após os tratamentos com os antagonistas e produtos alternativos. Foram determinados o Período de Incubação (PI), Severidade da doença (SEV), Redução da severidade da doença (RSD\%) e Área abaixo da curva de progresso da doença (AACPD). Todos os tratamentos testados apresentaram maiores valores de PI e RSD\% e menores valores de SEV e AACPD quando comparados à testemunha. Fosfito de cálcio, C116, Lms, Lma e fosfito de potássio foram significativamente superiores quando comparados como demais tratamentos. Pcc foi resistente ao Kasumin ${ }^{\circledR}$, possuindo SEV e AACPD que não diferiram significativamente da testemunha.
\end{abstract}

Palavras-chave: Pectobacterium carotovorum subsp. carotovorum. Controle biológico. Controle alternativo. Fitopatologia.

\begin{abstract}
For the control of soft rot caused by Pectobacterium carotovorum subsp. carotovorum (Pcc) in chili, 10 treatments were evaluated: Bacillus spp.: isolated C116 (B. pumilus); Yeasts: isolated Lma (Rhodotorula aurantiaca) and Lms (R. glutinis); Potassium phosphite and calcium, calcium sources: $\mathrm{CaCl} 2, \mathrm{Ca}(\mathrm{CO} 3) 2$ and $\mathrm{Ca}(\mathrm{SO} 4) 2$; fungicidal/bactericidal organic Antica ${ }^{\circledR}$; Kasumin ${ }^{\circledR}$ antibiotic. After determining the concentration of the antagonist and alternative products by antibiogram testing, testing was performed in vivo by pathogen inoculation, six hours after treatment with antagonists and alternative products. We determined the Incubation Period (PI), severity of illness $(\mathrm{SEV})$, reduction of disease severity (RSD\%) and area under the disease progress curve (AUDPC). All treatments showed higher PI and RSD\% and lower values of SEV and AUDPC compared to the control. Calcium phosphite, C116, Lms, Lma and potassium phosphite were significantly higher when compared to other treatments. Pcc was resistant Kasumin ${ }^{\circledR}$, possessing SEV and AUDPC did not differ significantly from control.
\end{abstract}

Key words: Pectobacterium carotovorum subsp. carotovorum. Biological control. Alternative control. Phytopathology.

\footnotetext{
*Autor para correspondência

${ }^{1}$ Recebido para publicação em 14/11/2013; aprovado em 18/06/2014

Pesquisa realizada pelo autores na Universidade Federal Rural de Pernambuco

${ }^{2}$ Departamento de Agronomia, Área de Fitossanidade, Universidade Federal Rural de Pernambuco, Recife-PE, Brasil, matheus.silvaesilva@ gmail.com, conradoqueiroz@hotmail.com, agronomajessica@gmail.com, linsnina@hotmail.com

${ }_{3}^{3}$ Departamento de Agronomia, Área de Fitossanidade, Universidade Federal Rural de Pernambuco, Rua Dom Manoel de Medeiros, s/n, Dois Irmãos, Recife-PE, Brasil, 52.171-900, s.oliveira@depa.ufrpe.br
} 


\section{INTRODUÇÃO}

O pimentão, Capsicum annuит L. (Solanaceae), é uma hortaliça de grande importância socioeconômica para o Brasil. Constitui uma excelente alternativa de produção para as áreas irrigadas e de sequeiro do semiárido nordestino, pois é de fácil adaptação às diversas condições edafoclimáticas (LORENTZ et al., 2002). No entanto, os frutos estão sujeitos a problemas fitossanitários que afetam a qualidade e causam grandes perdas na pós-colheita.

A podridão mole, causada pela bactéria Pectobacterium carotovorum subsp. carotovorum - Pcc (Jones) Hauben et al. (sin. Erwinia carotovora subsp. carotovora) (JABUONSKI; TAKATSU; REIFSCHNEIDER, 1986), é muito comum no Brasil, seja no campo ou na fase de pós-colheita, sendo um fator limitante para o cultivo de olerícolas, como o pimentão.

O manejo da podridão mole é muito difícil, uma vez que $P c c$ tem a capacidade de adaptação a uma larga faixa de temperatura que a mantém viável por longos períodos, sobrevivendo na água, no solo, em restos culturais infectados e na rizosfera/filosfera de plantas cultivadas ou invasoras (DE BOER; KELMAN, 2001; PÉROMBELON; VAN DER WOLF, 2002).

O uso de fungicidas em pós-colheita vem sofrendo uma série de restrições, que recaem principalmente sobre o seu efeito residual, que pode restringir a exportação dos frutos e a sua comercialização. Dessa forma, métodos alternativos de manejo na pós-colheita vêm sendo pesquisados em diversas culturas, destacando-se a utilização de fosfitos, fontes de cálcio, bem como o uso de leveduras e bactérias antagonistas (GOMES; SILVEIRA; MARIANO, 2005).

A ação dos fosfitos foi relatada inúmeras vezes contra diferentes patógenos das mais variadas plantas cultivadas (DIANESE; BLUM, 2010). Esses compostos não são fitotóxicos e possuem elevada atividade fungicida, podendo atuar diretamente inibindo o desenvolvimento dos fungos e, também, indiretamente ativando o sistema de defesa da planta hospedeira.

Redução de desordens fisiológicas, atraso na senescência e inibição de podridões na pós-colheita são alguns benefícios atribuídos à aplicação de sais de cálcio, devido a habilidade deste íon em se ligar às pectinas da parede celular, o que dificulta a degradação da mesma através de enzimas pectinolíticas produzidas por patógenos, como é o caso de $P c c$ (GOMES; SILVEIRA; MARIANO, 2005).

A utilização de leveduras e bactérias antagonistas no manejo de podridões em pós-colheita tem sido estudada por vários pesquisadores (BAZ et al., 2012; GOMES; SILVEIRA; MARIANO, 2005), existindo os produtos comerciais Aspire $^{\circledR}$ e Bio-save $110^{\circledR}$, à base de Candida oleophila I-182 e Pseudomonas syringae, respectivamente, para o manejo de diversas doenças fúngicas em diferentes culturas (SENHOR et al., 2009).

Considerando a carência de pesquisas com uso de fosfitos para o controle de bactérias fitopatogênicas, bem como a importância econômica da podridão mole e visando reduzir as perdas pós-colheita em pimentão, o objetivo para desenvolver este trabalho foi avaliar o efeito de antagonistas e produtos alternativos no manejo da infecção causada por $P$. carotovorum subsp. carotovorum.

\section{MATERIAL E MÉTODOS}

O isolado de $P$. carotovorum subsp. carotovorum (Pcc-19) foi obtido da Coleção de Culturas do Laboratório de Fitobacteriologia, do Programa de Pós-Graduação em Fitopatologia da Universidade Federal Rural de Pernambuco, sendo provenientes de frutos de pimentão com infecção natural, estando preservado em água destilada esterilizada (ADE).

$\mathrm{O}$ teste de patogenicidade foi realizado introduzindo-se a ponta de um palito esterilizado, após tocar em uma colônia de $P c c$, em pimentões sadios. Os frutos foram mantidos em câmara úmida (umidade relativa de $92 \pm 4 \%$ ) por 48 horas, até o aparecimento dos sintomas típicos da doença, procedendo-se ao reisolamento do patógeno.

Para o manejo da podridão mole, foram avaliados 10 tratamentos. Dentre eles: Bacillus spp.: isolado C116 (B. pumilus), nas concentrações de 3,87; 5,87; 7,87; 9,87 x $10^{10} \mathrm{UFC} / \mathrm{mL}$; Leveduras: isolados Lma (Rhodotorula aurantiaca) e Lms ( $R$. glutinis), nas concentrações de 3,$87 ; 5,87 ; 7,87 ; 9,87 \times 10^{10} \mathrm{UFC} / \mathrm{mL}$; Compostos de fosfitos: Fosfito de potássio - 58\% $\mathrm{P}_{2} \mathrm{O}_{5}+38 \% \mathrm{~K}_{2} \mathrm{O}$ e Fosfito de cálcio - $64 \% \mathrm{P}_{2} \mathrm{O}_{5}+18 \% \mathrm{Ca}$, nas concentrações de $2 ; 4 ; 6 ; 8 \%(\mathrm{p} / \mathrm{v})$; Fontes de cálcio: cloreto de cálcio $\left(\mathrm{CaCl}_{2}\right)$, carbonato de cálcio $\left[\mathrm{Ca}\left(\mathrm{CO}_{3}\right)_{2}\right]$ e nitrato de cálcio $\left[\mathrm{Ca}\left(\mathrm{SO}_{4}\right)_{2}\right]$, nas concentrações de $1 ; 2 ; 4 ; 6 \%(\mathrm{p} / \mathrm{v})$; fungicida/bactericida orgânico Antica ${ }^{\circledast}$ - $10 \mathrm{~g} / \mathrm{kg}$ ácido lático + ácido alpha hidroxy, nas concentrações de 10; 15; 20; $25 \%$ (p/v); antibiótico Kasumin ${ }^{\circledR}$ - Casugamicina $20 \mathrm{~g} / \mathrm{L}$, nas concentrações de 150, 200, 240 e $300 \mathrm{~mL} / 100 \mathrm{~L}$ de $\mathrm{H}_{2} \mathrm{O}$, além da testemunha, com a utilização de ADE.

Para testar a sensibilidade de $P c c-19$ a diferentes antagonistas e produtos alternativos em condições in vitro, realizou-se o teste de antibiograma (MARIANO et al., 2005).

O isolado Pcc-19 foi cultivado em meio Caseína ácido hidrolizada-peptona-glicose (CPG) por 24 - 48 horas a uma temperatura de $25 \pm 2{ }^{\circ} \mathrm{C}$. Após este período, $\mathrm{ADE}$ foi adicionada a placa de Petri contendo o crescimento bacteriano e a concentração da suspensão foi ajustada em fotocolorímetro (Analyser ${ }^{\circledR}$ ) a $570 \mathrm{~nm}$ de absorbância, onde 
$\mathrm{A}_{570}=0,36$ equivale a $1 \times 10^{9} \mathrm{UFC} / \mathrm{mL}$. As placas foram incubadas a uma temperatura de $25 \pm 2{ }^{\circ} \mathrm{C}$. As leituras foram realizadas após 48 horas, medindo-se os halos de inibição. Para definição da melhor concentração foi realizada análise de regressão, representando os 10 tratamentos em quatro diferentes concentrações, mais a testemunha. Foram utilizados cinco repetições por tratamento, sendo a unidade experimental constituída por quatro placas.

Para a avaliação in vivo os frutos de pimentão foram lavados em água corrente com sabão, imersos em solução de hipoclorito de sódio $0,7 \%$ por 2 minutos, lavados três vezes com ADE e colocados em prateleiras para retirar o excesso de umidade sob temperatura ambiente $\left(25 \pm 2{ }^{\circ} \mathrm{C}\right)$. Em seguida, os frutos foram pulverizados com os 10 tratamentos nas concentrações pré-definidas nos testes in vitro. Após seis horas foram marcados dois círculos na superfície dos frutos, um em cada extremidade, e efetuados dois ferimentos ( $2 \mathrm{~mm}$ de profundidade) equidistantes em cada área, com o auxílio de um alfinete entomológico. Sob os ferimentos foi depositado $10 \mu \mathrm{l}$ da suspensão de Pcc-19 (1x10 $\mathrm{UFC} / \mathrm{ml})$ contendo espalhante adesivo Tween $80(0,05 \%)$. Os frutos foram incubados em câmara úmida (umidade relativa de $92 \pm 4 \%$ ) segundo a metodologia de Melo et al. (1995), e mantidos em temperatura ambiente $\left(25 \pm 2{ }^{\circ} \mathrm{C}\right)$. As avaliações foram realizadas a cada seis horas após a inoculação inicial, sendo a última realizada 48 horas após inoculação.

Foram medidos os diâmetros das lesões em sentidos diametralmente opostos, para se determinar os seguintes componentes epidemiológicos: a) Período de incubação da doença (PI), que corresponde ao período entre a inoculação e o início dos sintomas, em horas; b) Severidade da doença (SEV), obtida pelo comprimento da lesão em sentidos diametralmente opostos; c) Redução da severidade da doença (RSD\%) em relação à testemunha, pela fórmula RSD\% $=[(\mathrm{DLT}-\mathrm{DLTr}) / \mathrm{DLT}] \times 100$, onde DLT = diâmetro da lesão na testemunha, DLTr = diâmetro da lesão no tratamento; d) Área abaixo da curva de progresso da doença (AACPD), calculada pela expressão: AACPD $=\Sigma($ y i + y i+1)/2.dti, onde y i e y i+1 são os valores de severidade observados em duas avaliações consecutivas e dti o intervalo entre as avaliações.

O delineamento experimental foi inteiramente casualizado, com 10 tratamentos, mais a testemunha, que não recebeu nenhum tratamento de pós-colheita. Foram utilizados oito repetições por tratamento, sendo a unidade experimental constituída por dois furos em cada fruto.

Os dados obtidos foram analisados quanto aos pressupostos da análise de variância (ANOVA) e submetidos a testes de comparação de média (Tukey) ao nível de $5 \%$ de probabilidade ou de regressão polinomial, com o auxílio do programa STATISTIX ${ }^{\circledR}$ (versão 9.0, Analytical Software, Tallahassee).

\section{RESULTADOS E DISCUSSÃO}

O teste de patogenicidade foi realizado com sucesso, ao reproduzir os sintomas de podridão mole quando inoculada em pimentão sadio com o auxílio do palito de dente esterilizado, demonstrado que o isolado de Pcc-19 ainda era patogênico.

Com relação à determinação das concentrações, a análise de regressão de todos os produtos testados melhor se adequou ao formato polinomial (Figura 1), onde foram obtidos os maiores valores do coeficiente de determinação $\left(R^{2}\right)$.

Com isso, as dosagens foram definidas para o teste in vivo com relação ao halo de inibição do crescimento bacteriano para cada produto testado sendo escolhida, sempre, a concentração que se obteve o maior nível de inibição (Figura 1). Foram escolhidas as seguintes concentrações para cada tratamento testado: B. pumilus isolado C116 - 9,87 x $10^{10} \mathrm{UFC} / \mathrm{mL}$ (Figura 1H); Leveduras biocontroladoras, isolado Lma - 5,87 x $10^{10} \mathrm{UFC} / \mathrm{mL}$ (Figura 1I) e isolado Lms - 7,87 x 10 ${ }^{10} \mathrm{UFC} / \mathrm{mL}$ (Figura 1J); Fosfito de potássio - 8\% (p/v) (Figura 1A); Fosfito de cálcio - 4\% (p/v) (Figura 1B); Cloreto de cálcio - 4\% (p/v) (Figura 1C); Carbonato de cálcio - 8\% (p/v) (Figura 1D); Nitrato de cálcio - 6\% (p/v) (Figura 1E); Antica® - 20\% (p/ v) (Figura 1F); Kasumin ${ }^{\circledR}-150 \mathrm{~mL} / 100 \mathrm{~L}$ de $\mathrm{H}_{2} \mathrm{O}$ (Figura 1G). O isolado Pcc-19 apresentou sensibilidade a todos os produtos testados, com exceção do antibiótico Kasumin $®$ onde, nesse caso, o isolado de Pcc se mostrou resistente. O mesmo ocorreu em trabalhos realizados por Gama et al. (2011) ao realizar teste de sensibilidade in vitro com a bactéria Acidovorax citrulli utilizando o Kasumin ${ }^{\circledR}$ como tratamento controle.

No teste in vivo, dentre os tratamentos alternativos avaliados, o que demonstrou os maiores valores de PI e RSD\% e os menores valores de SEV e AACPD foi o Fosfito de cálcio, demonstrando ser o melhor produto no manejo pós-colheita da podridão mole em pimentão no presente ensaio. Pelo fosfito de potássio também se obteve valores que diferiram estatisticamente e superaram a testemunha $(\mathrm{P} \leq 0,05)$ em todas as variáveis analisadas. $\mathrm{O}$ efeito dos fosfitos no manejo de doenças pós-colheita já foi citado por outros autores. Brackmann et al. ( 2004) verificaram que frutos tratados com fosfito $\mathrm{K}+\mathrm{CaCl}_{2}$ foram tão eficientes quanto o fungicida padrão Iprodione, tanto em relação a incidência de podridão quanto ao diâmetro médio das lesões. Blum et al. (2007) relataram que maçãs 'Fuji' e 'Gala' imersas em água com fosfito $\mathrm{Ca} / \mathrm{B}(1,50 \mathrm{ml} / \mathrm{L})$, fosfito $\mathrm{K}(0,50-1,50 \mathrm{ml} / \mathrm{L})$ ou benomil (150 ppm) foram 
Figura 1 - Influência da concentração de produtos alternativos e microrganismos antagonistas na formação do halo de inibição de Pectobacterium carotovorum subsp. carotovorum. Produtos alternativos (A-G): Figura 1A. Fosfito de potássio, Figura 1B. Fosfito de cálcio, Figura 1C. Cloreto de cálcio, Figura 1D. Carbonato de cálcio, Figura 1E. Nitrato de cálcio, Figura 1F. Antica® e Figura 1G. Kasumin®. Microrganismos antagonistas (H-J): Figura 1H. Bacillus pumilus - C116, Figura 1I. Rhodotorula aurantiaca - Lma e Figura 1J. R. glutinis - Lms
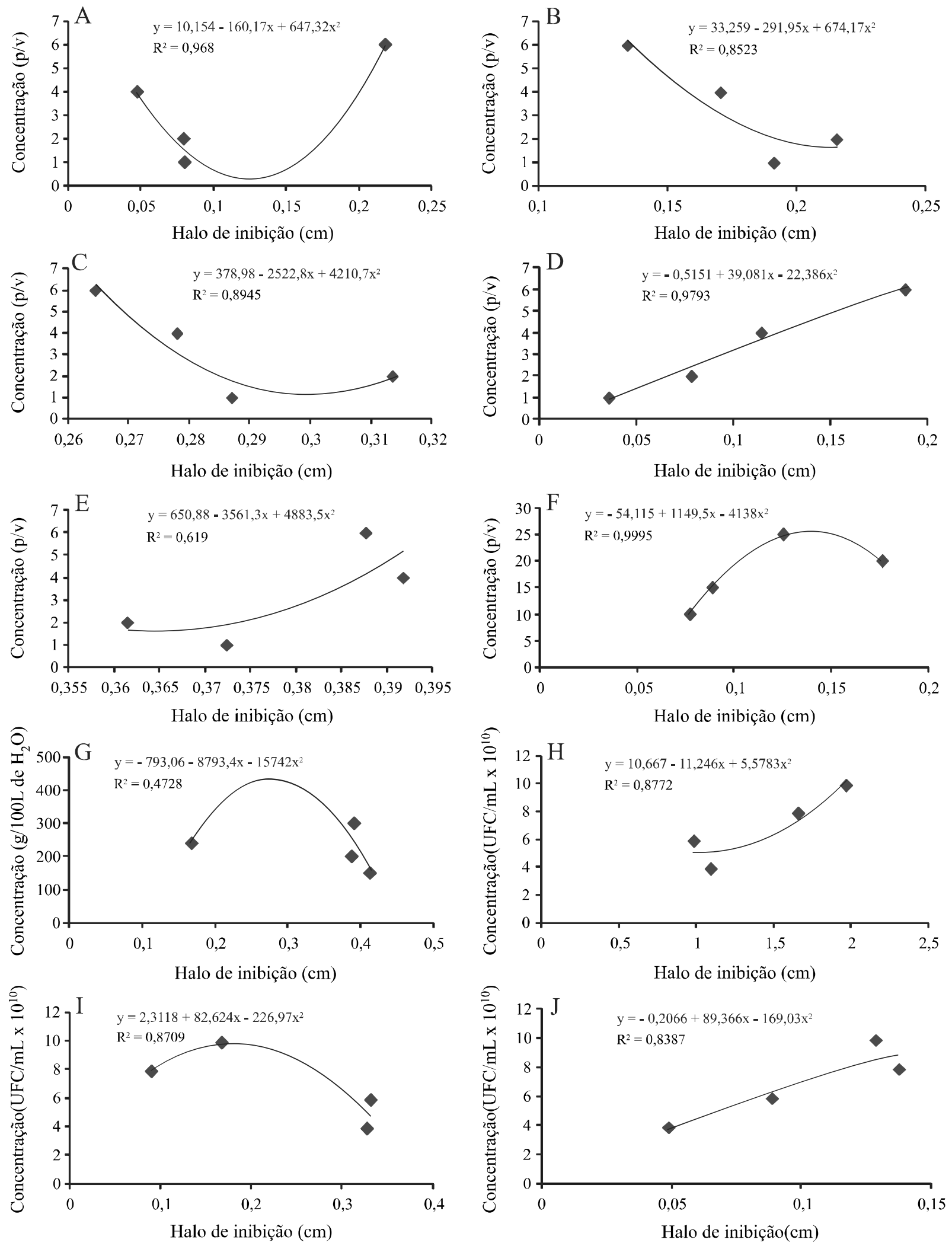
menos afetados pelo mofo-azul (Penicillium expansum), enquanto que Brackmann et al. (2004) notaram que em relação ao diâmetro das lesões, os frutos tratados com fosfito $\mathrm{Ca}+\mathrm{B}(300 \mathrm{~mL} / 100 \mathrm{~L})$ apresentaram lesões maiores que os demais, demonstrando que este tratamento não foi eficiente no controle do desenvolvimento de podridões póscolheita em maçãs 'Fuji'. Em outros trabalhos, Lins et al. (2011) também testou produtos alternativos no controle da podridão peduncular em manga 'Tommy Atkins', inoculada com Lasiodiplodia theobromae, dentre eles o Cloreto de cálcio e o Fosfato de potássio, nas dosagens de 0,13 mmol e $50 \mathrm{mmol}$, respectivamente, e estes foram mais eficientes no controle alternativo da podridão. No entanto, os produtos a base de cálcio e potássio (fosfitos) não apresentaram nenhuma eficiência contra as podridões avaliadas no trabalho.

Brackmann et al. (2005), os fosfitos apresentam variabilidade considerável em relação à eficiência e persistência entre as mais diversas espécies de plantas, tecido do fruto, patógeno, época e frequência de aplicação. De acordo com os autores essa variabilidade pode estar relacionada com o fato de que no presente trabalho o Fosfito de cálcio tenha sido mais eficiente do que o Fosfito de potássio. Existem poucos trabalhos sobre como o fosfito atua sobre as bactérias, mas de acordo com Ribeiro Junior et al. (2006) o fosfito também possui ação contra as doenças bacterianas.

É pouco conhecido o efeito dos fosfitos sobre as várias fases do ciclo de vida de outros patógenos (BRACKMANN et al., 2005). Vários trabalhos demonstram que o fosfito atua diretamente sobre o fungo (WILKINSON; SHEANER; JACKSON, 2001). Outros, no entanto, atribuem sua eficiência a um efeito indireto por meio da ativação dos mecanismos de defesa da planta (JACKSON, 2000). Neste caso, a aplicação do fosfito estimularia a produção de fitoalexinas, produzidas pelas plantas quando estas são infectadas por algum patógeno (DANIEL; GUEST, 2006) e podem atuar também reduzindo o crescimento micelial, a formação de esporângios e a liberação de zoósporos.

Dentre os tratamentos baseados no uso de antagonistas (Tabela 1), a bactéria C116 (Bacillus pumilus) e a levedura Lms (Rhodotorula glutinis) também revelaram resultados satisfatórios com relação ao controle da podridão mole do pimentão e os mesmos não diferiram significativamente do tratamento onde foi utilizado o Fosfito de cálcio, indicando serem possíveis alternativas no manejo pós-colheita dessa doença. O isolado de levedura Lma (R. aurantiaca) apesar de não ter tido um desempenho tão satisfatório quanto aos isolados anteriormente citados, diferiu significativamente da testemunha $(\mathrm{P} \leq 0,05)$ em todas as variáveis epidemiológicas analisadas, demonstrando potencial de uso nesse patossistema.
Bactérias do gênero Bacillus levam vantagem no controle biológico de doenças porformaremendósporosque favorecem sua sobrevivência, facilitando a manipulação, formulação, bem como suportar relativamente longos períodos de armazenamento mantendo sua eficiência (WARRIOR; KONDURU; VASUDEVAN, 2002), sendo sua utilização, portanto, uma alternativa na redução de podridões em pós-colheita de diversas culturas. Antoniolli et al. (2011) verificaram que o uso de B. amyloliquefaciens reduziu significativamente as podridões causadas por Botrytis e Rhizopus em framboesa, sem interferir nas suas características físico-químicas; Warrior, Konduru e Vasudevan (2002) demonstraram que isolados B. subtilis (PPCB001) e B. amyloliquefaciens (PPCB004) associados às embalagens de atmosfera modificada reduziram a incidência de Penicillium crustosum em fruto de laranja 'Valencia'; Ongena et al. (2005) relataram que isolado de B. subtilis (M4) reduziram a população de Botrytis cinerea em maçã em mais de $70 \%$ em até 15 dias após a inoculação, em tratamento 24horas antes da inoculação como patógeno. Segundo Leelasuphakul, Hemmanee e Chuencitt (2008), Bacillus spp. podem apresentar diferentes mecanismos de ação sobre os fitopatógenos, como competição (por espaço e nutrientes), síntese de compostos voláteis e, principalmente síntese de substâncias antimicrobianas (antibiose), o que muitas vezes é visto como desvantagem para o consumo de produtos consumidos in natura.

O uso de leveduras no manejo de doenças póscolheita, já demonstrou ser bastante eficiente e muitas vezes são consideradas até similares ao tratamento químico. Como exemplo, pode ser mencionado Blum et al. (2004) que ao realizarem testes em laboratório utilizando a levedura Cryptococcus laurentii em pós-colheita, obteveram uma redução das podridões (Glomerella cingulata, Penicillium expansum e Pezicula malicorticis) da maçã tanto quanto os fungicidas testados (thiabendazol e iprodione). De acordo com Sanhueza (1998), é preferível utilizar leveduras na proteção de frutos que serão consumidos in natura, pois esses microrganismos não são, geralmente, produtores de antibióticos, elementos considerados contaminantes químicos, tal como ocorre com Bacillus spp. Entre os principais mecanismos de ação das leveduras encontra-se a competição por nutrientes, a indução de resistência e o parasitismo (MARIANO et al., 2000). A atividade biocontroladora de leveduras antagonistas depende da presença de um grande número de células antagonistas no sítio de ferimento, sendo este requerimento considerado um possível fator limitante para a formulação de um produto biológico (GOMES; SILVEIRA; MARIANO, 2005). Alguns trabalhos mostraram a utilização das leveduras Cryptococcus spp. e Rhodotorula spp. no controle de $P$. expansum em maçãs; A. pullulans, Candida vanderwaltii e C. oleophila contra $B$. cinerea em uva e kiwi; Trichoderma atroviride 
Tabela 1 - Efeito de antagonistas e produtos alternativos, no manejo da Pectobacterium carotovorum subsp. carotovorum em pimentão, avaliados pelo período de incubação (PI), severidade da doença (SEV), redução da severidade da doença (RSD) e área abaixo da curva de progresso da doença (AACPD)

\begin{tabular}{llllc}
\hline \multicolumn{1}{c}{ Tratamento } & PI (horas) & RSD $^{3}$ & AACPD $^{3}$ \\
\hline Lma $^{4}$ & $43,50 \mathrm{abc}^{1}$ & $0,30 \mathrm{a}$ & $73,89 \mathrm{ab}$ & $4,73 \mathrm{ab}$ \\
$\mathrm{Lms}^{4}$ & $49,50 \mathrm{ab}$ & $0,19 \mathrm{a}$ & $82,55 \mathrm{ab}$ & $2,57 \mathrm{ab}$ \\
$\mathrm{C} 116^{5}$ & $49,12 \mathrm{ab}$ & $0,12 \mathrm{a}$ & $90,75 \mathrm{a}$ & $1,84 \mathrm{a}$ \\
Fosfito de Cálcio & $51,37 \mathrm{a}$ & $0,09 \mathrm{a}$ & $90,86 \mathrm{a}$ & $0,90 \mathrm{a}$ \\
Fosfito de Potássio & $37,87 \mathrm{bcd}$ & $0,66 \mathrm{ab}$ & $55,88 \mathrm{abc}$ & $9,77 \mathrm{bc}$ \\
$\mathrm{CaCl}$ & $23,25 \mathrm{e}$ & $1,37 \mathrm{~cd}$ & $17,68 \mathrm{c}$ & $19,15 \mathrm{de}$ \\
$\mathrm{Ca}\left(\mathrm{CO}_{3}\right)_{2}$ & $31,50 \mathrm{de}$ & $1,07 \mathrm{bc}$ & $24,71 \mathrm{bc}$ & $14,29 \mathrm{~cd}$ \\
$\mathrm{Ca}\left(\mathrm{SO}_{4}\right)_{2}$ & $22,87 \mathrm{e}$ & $1,56 \mathrm{~cd}$ & $-5,95 \mathrm{c}$ & $20,73 \mathrm{de}$ \\
$\mathrm{Antica}{ }^{8}$ & $32,62 \mathrm{cde}$ & $1,10 \mathrm{bc}$ & $50,76 \mathrm{bc}$ & $15,93 \mathrm{~cd}$ \\
$\mathrm{Kasumin}{ }^{-}$ & $25,87 \mathrm{e}$ & $1,73 \mathrm{~cd}$ & $13,28 \mathrm{c}$ & $20,06 \mathrm{de}$ \\
Testemunha & $14,62 \mathrm{f}$ & $2,15 \mathrm{~d}$ & na & $32,45 \mathrm{e}$ \\
$(\mathrm{CV} \%)$ & 16,79 & 26,84 & 40,32 & 47,25 \\
\hline
\end{tabular}

${ }^{1}$ Médias seguidas pela mesma letra minúscula dentro da coluna não diferem estatisticamente entre si pelo teste de LSD a 5\% de probabilidade. ${ }^{2}$ Os dados referentes ao PI foram transformados pela equação $\log (\mathrm{x}+1)$ para melhor atender aos pressupostos da análise de variância (ANOVA). ${ }^{3} \mathrm{Os}$ dados referentes a SEV, RSD $(\%)$ e AACPD foram transformados pela equação Sqrt $(\mathrm{x}+0,5)$ para melhor atender aos pressupostos da análise de variância (ANOVA). ${ }^{4}$ Leveduras: isolado Lma (Rhodotorula aurantiaca) e isolado Lms (R. glutinis). ${ }^{5}$ Bacillus spp.: isolado C116 (B. pumilus). ${ }^{6}$ Não aplicável

e $T$. viride contra $M$. fructicola em pêssegos e ameixas; Pseudomonas syringae no controle de $M$. fructicola em pêssegos; A. pullulans contra B. cinerea e M. laxa em cerejas (DROBYA et al., 2003; NUNES et al., 2001).

Com relação às fontes de cálcio, excetuando o $\mathrm{Ca}\left(\mathrm{CO}_{3}\right)_{2}$, todos os outros produtos testados foram eficientes para a redução significativa $(p \leq 0,05)$ apenas nos valores de PI quando comparados com a testemunha (Tabela 1). Com relação às outras variáveis analisadas, SEV, RSD\% eAACPD nenhuma diferença significativa foi observada ( $\mathrm{p} \geq 0,05$ ). Esses resultados diferem dos obtidos por Gomes, Silveira e Mariano (2005), onde todas as fontes e concentrações de cálcio avaliadas, foram eficientes na RSD\% da podridão mole, destacando-se a aplicação de $\mathrm{CaCl}_{2}$ a $8 \%$ com a redução da doença de $69,5 \%$, embora sem diferir significativamente das concentrações a 1 e $4 \%$. Esses resultados podem estar provavelmente relacionados com os métodos de inoculação que foram utilizados no presente trabalho. Uma vez que Conway et al. (1992) relataram a eficiência da infiltração a vácuo de $\mathrm{CaCl}_{2}$ a $8 \%$, reduzindo em $25 \%$ o apodrecimento pós-colheita de maçã e batata. Este método de aplicação de cálcio, segundo McGuire e Kelman (1984), é o mais eficiente no controle da podridão de Pectobacterium em batata. Esses autores verificaram que $\mathrm{Ca}\left(\mathrm{NO}_{3}\right)_{2}$, nas concentrações de 0,$1 ; 0,6$ e $1,2 \%$, foram capazes de reduzir a severidade da podridão mole em batata causada por $P$. carotovorum subsp. atrosepticum, em 58,3; 83,9 e 100\%, respectivamente.
$\mathrm{O}$ antibiótico Kasumin ${ }^{\circledR}$ e o fungicida/bactericida orgânico Antica ${ }^{\circledR}$ não diferiram significativamente entre si $(\mathrm{p} \leq 0,05)$ com relação a todas as variáveis epidemiológicas analisadas (Tabela 1). Nas variáveis SEV e AACPD, o Kasumin $^{\circledR}$ proporcionou valores que não diferiram estatisticamente da testemunha, além de ter sido um dos tratamentos que apresentaram menor RSD\%, mostrando uma estreita associação entre $P c c-19$ e o princípio ativo Casugamicina, sugerindo talvez uma resistência constitutiva no DNA cromossomal ou plasmidial (GAMA et al., 2011). O fungicida/bactericida orgânico Antica ${ }^{\circledR}$, apesar de ter sido significativamente superior à testemunha $(\mathrm{p} \leq 0,05)$ em todas as variáveis epidemiológicas analisadas, há necessidade de estudos posteriores para se determinar o seu verdadeiro efeito na redução da podridão mole, uma vez que na literatura pesquisas com a sua utilização em pós-colheita são escassos.

\section{CONCLUSÕES}

1. Os produtos alternativos, fosfito de cálcio, fosfito de potássio e os microrganismos antagonistas, C116, Lms e Lma foram eficientes no manejo pós-colheita da podridão mole do pimentão para todas as variáveis analisadas;

2. Dentre todos os tratamentos (produtos alternativos, microrganismos antagonistas e fungicida/bactericida), o fosfito de cálcio se destacou, sendo um produto em potencial para ser utilizado no manejo da doença. 
3. O bactericida Kasumin® não se mostrou eficiente no manejo pós-colheita da podridão mole do pimentão;

4. Há necessidade de estudos mais aprofundados para verificar o fungicida/bactericida orgânico Antica ${ }^{\circledR}$ como possível alternativa no manejo pós-colheita da podridão mole do pimentão.

\section{AGRADECIMENTOS}

Os autores agradecem ao Conselho Nacional de Desenvolvimento Tecnológico e Científico (CNPq) e a Fundação de Amparo à Ciência e Tecnologia do Estado de Pernambuco (FACEPE) pela concessão de bolsa de estudo e pelo financiamento parcial dos experimentos.

\section{REFERÊNCIAS}

ANTONIOLLI, L. R et al. Controle alternativo de podridões pós-colheita de framboesas. Pesquisa Agropecuária Brasileira, v. 46, n. 9, p. 979-984, 2011.

BAZ, M. et al. Control of potato soft rot caused by Pectobacterium carotovorum and Pectobacterium atrosepticum by Moroccan actinobacteria isolates. World Journal Microbiol Biotechnology, v. 28, n. 1, p.303-11, 2012.

BLUM, L. E. B. et al. Cryptococcus laurentii aplicado em PósColheita reduz Podridões em maçãs. Fitopatologia Brasileira, v. 29 , n. 4 , p. 433-436, 2004.

BLUM, L.E. B. et al. Fosfitos aplicados em pós-colheita reduzem o mofo azul em maçãs 'Fuji' e 'Gala'. Revista Brasileira de Fruticultura, v. 29, n. 2, p. 265-268, 2007.

BRACKMANN, A. et al. Fosfitos para o controle de podridões pós-colheita em maçãs 'Fuji' durante o armazenamento refrigerado. Ciência Rural, v. 34, n. 4, p. 1039-1042, 2004.

BRACKMANN, A. et al. Controle de podridão pós colheita de Penicillium spp., em maçã 'Fuji' com fosfitos e fungicidas. Revista Brasileira de Agrociência, v. 11, n. 2, p. 251-254, 2005.

CONWAY, W. et al. Calcium treatment of apples and potatoes to reduce postharvest decay. Plant Disease, v. 76, n. 4, p. 329-334, 1992.

DANIEL, R.; GUEST, D. Defence responses induced by potassium phosphonate in Phytophthora palmivora-challenged Arabidopsis thaliana. Physiological and Molecular Plant Pathology, v. 67, n. 3/5, p. 194-201, 2006.

DE BOER, S. H.; KELMAN, A. Erwinia soft rot group. In: SCHAAD, N. W.; JONES J. B.; CHUN, W. (Ed.). Laboratory Guide for Identification of Plant Pathogenic Bacteria. 3th ed. Saint Paul, American Phytopathological Society, 2001. p. 56-72.

DIANESE, A. C.; BLUM, L. E. B. Uso de fosfitos no manejo de doenças fungicas de fruteiras e soja. Brasília: EMBRAPA, 2010. 29p.
DROBYA, S. et al. Influence of food additives on the control of postharvest rots of apple and peach and efficacy of the yeastbased biocontrol product aspire. Postharvest Biology and Technology, v. 27, n. 2, p. 127-135, 2003.

GAMA, M. A. S. et al. Polyphasic characterization of pigmented strains of Xanthomonas pathogenic to cashew trees. Plant Disease, p. 95, n. 7, p.793-802, 2011.

GOMES, A. M. A.; SILVEIRA, E. B.; MARIANO, R. L. R. Tratamento pós-colheita com cálcio e microrganismos para controle da podridão-mole em tomate. Horticultura Brasileira, v. 23, n. 1, p. 108-111, 2005.

JABUONSKI, R. E.; TAKATSU, A.; REIFSCHNEIDER, F. J. B. Levantamento e identificação de espécies de Erwinia de diferentes plantas hospedeiras e regiões do Brasil. Fitopatologia Brasileira, v. 11, n. 1, p. 185-195, 1986.

JACKSON, T. J.Action of the fungicide phosphite on Eucaliptus marginata inoculated with Phytophthora cinnamomi. Plant Pathology, v. 49, n. 1, p. 147-154, 2000.

LEELASUPHAKUL, W.; HEMMANEE, P.; CHUENCHITT, S. Growth inhibitory properties of Bacillus subtilis strains and their metabolites against the green mold pathogen (Penicillium digitatum Sacc.) of citrus fruit. Postharvest Biology and Technology, v. 48, n. 1, p. 113-121, 2008.

LINS, S. R. O. et al. Controle alternativo da podridão peduncular em manga. Summa Phytopathologica, v. 37, n. 3, p. 121-126, 2011.

LORENTZ, L. H. et al. Estimativa da amostragem para pimentão em estufa plástica. Horticultura Brasileira, In: 52 Congresso Brasileiro de Horticultura, Salvador. Resumos... Salvador, 2002. 1 CD-ROM.

MARIANO, R. L. R. et al . Biocontrole de doenças de plantas. In: TORRES, J. B.; MICHEREFF, S. J. (Ed.) Desafios do manejo integrado de pragas e doenças. Recife: Imprensa Universitária, 2000. p. 78-111.

MARIANO, R. L. R. et al. Produtos biológicos, químicos, e alternativos para controle de bactérias fitopatogênicas. In: MARIANO, R. L. R.; SILVEIRA, E. B. (Coord.) Manual de práticas em Fitobacteriologia. Recife: Universitária, 2005. p. 115-117.

MELO, R. A. G. et al. Controle biológico da podridão-mole do pimentão (Capsicum annum) causada por Erwinia carotovora subsp. carotovora. Summa Phytopathologica, v. 21, n. 3/4, p. 206-212, 1995.

MCGUIRE, R. G.; KELMAN, A. Reduced severity or Erwinia soft rot in potato tuber with increase calcium content. Physiology and Biochemistry, v. 74, n. 10, p. 1250-1256, 1984.

NUNES, C. et al. Biological control of postharvest pear diseases using a bacterium, Pantoea agglomerans CPA-2. International Journal of Food Microbiology, v. 70, n. 1/2, p. 53-61, 2001.

ONGENA, M. et al. Bacillus subtilis M4 decreases plant susceptibility towards fungal pathogens by increasing host resistance associated with differential gene expression. Applied Microbiology and Biotechnology, v. 67, n. 5, p. 692-698, 2005.

PÉROMBELON, M. C. M.; VAN DER WOLF, J. M. Methods for the detection and quantification of Erwinia carotovora subsp. 
atroseptica (Pectobacterium carotovorum subsp. atrosepticum) on potatoes: a laboratory manual. 2. ed. Invergowrie. Scottish Crop Research Institute. 2002, 82 p.

RIBEIRO JUNIOR, P. M. et al. Fosfito de Potássio na indução de resistência a Verticillium dahliae Kleb, em mudas de cacaueiro (Theobroma cacao L.). Ciências Agrotécnicas, v. 30, n. 4 , p. $629-636,2006$.

SANHUEZA, R. M. V. Leveduras para o controle de fitopatógenos. In: SIMPÓSIO DE CONTROLE BIOLÓGICO, 6., 1998.,Rio de Janeiro. Anais... Rio de Janeiro: FIOCRUZ, 1998. p. 340-343.
SENHOR, R. F. et al. Manejo de doenças pós-colheita. Revista Verde, v. 4, n. 1, p. 00-13, 2009.

WARRIOR, P.; KONDURU, K.; VASUDEVAN, P. Formulation of biological control agents for pest and disease management. In: GNANAMANICKAM, S. S. (Ed.). Biological control of crop diseases. New York: Marcel Dekker, 2002. p. 421-441.

WILKINSON, C. J.; SHEARER, B. L.; JACKSON, T. J. Variation in sensitivity of Western Australian isolates of Phytophthora cinnamomi to phosphates in vitro. Plant Pathology, v. 50, n. 1, p. 83-89, 2001. 